\title{
Smart Shirts for Monitoring Physiological Parameters: Scoping Review
}

Hamzeh Khundaqji ${ }^{1}$, BSc, DPT; Wayne Hing ${ }^{1}$, PhD; James Furness ${ }^{1}$, PhD; Mike Climstein ${ }^{2,3}$, PhD

${ }_{1}^{1}$ Faculty of Health Sciences \& Medicine, Bond University, Gold Coast, Australia
${ }^{2}$ School of Health and Human Sciences, Southern Cross University, Bilinga, Australia
${ }^{3}$ Physical Activity, Lifestyle, Ageing and Wellbeing Faculty Research Group, University of Sydney, Sydney, Australia

Corresponding Author:

Hamzeh Khundaqji, BSc, DPT

Faculty of Health Sciences \& Medicine

Bond University

2 Promethean Way

Gold Coast, 4226

Australia

Phone: 610431443642

Email: hamzeh.khundaqii@student.bond.edu.au

\section{Abstract}

Background: The recent trends of technological innovation and widescale digitization as potential solutions to challenges in health care, sports, and emergency service operations have led to the conception of smart textile technology. In health care, these smart textile systems present the potential to aid preventative medicine and early diagnosis through continuous, noninvasive tracking of physical and mental health while promoting proactive involvement of patients in their medical management. In areas such as sports and emergency response, the potential to provide comprehensive and simultaneous physiological insights across multiple body systems is promising. However, it is currently unclear what type of evidence exists surrounding the use of smart textiles for the monitoring of physiological outcome measures across different settings.

Objective: This scoping review aimed to systematically survey the existing body of scientific literature surrounding smart textiles in their most prevalent form, the smart shirt, for monitoring physiological outcome measures.

Methods: A total of 5 electronic bibliographic databases were systematically searched (Ovid Medical Literature Analysis and Retrieval System Online, Excerpta Medica database, Scopus, Cumulative Index to Nursing and Allied Health Literature, and SPORTDiscus). Publications from the inception of the database to June 24, 2019 were reviewed. Nonindexed literature relevant to this review was also systematically searched. The results were then collated, summarized, and reported.

Results: Following the removal of duplicates, 7871 citations were identified. On the basis of title and abstract screening, 7632 citations were excluded, whereas 239 were retrieved and assessed for eligibility. Of these, 101 citations were included in the final analysis. Included studies were categorized into four themes: (1) prototype design, (2) validation, (3) observational, and (4) reviews. Among the 101 analyzed studies, prototype design was the most prevalent theme (50/101, 49.5\%), followed by validation (29/101, 28.7\%), observational studies $(21 / 101,20.8 \%)$, and reviews $(1 / 101,0.1 \%)$. Presented prototype designs ranged from those capable of monitoring one physiological metric to those capable of monitoring several simultaneously. In 29 validation studies, 16 distinct smart shirts were validated against reference technology under various conditions and work rates, including rest, submaximal exercise, and maximal exercise. The identified observational studies used smart shirts in clinical, healthy, and occupational populations for aims such as early diagnosis and stress detection. One scoping review was identified, investigating the use of smart shirts for electrocardiograph signal monitoring in cardiac patients.

Conclusions: Although smart shirts have been found to be valid and reliable in the monitoring of specific physiological metrics, results were variable for others, demonstrating the need for further systematic validation. Analysis of the results has also demonstrated gaps in knowledge, such as a considerable lag of validation and observational studies in comparison with prototype design and limited investigation using smart shirts in pediatric, elite sports, and emergency service populations.

(JMIR Mhealth Uhealth 2020;8(5):e18092) doi: 10.2196/18092 


\section{KEYWORDS}

wearable electronic devices; biomedical technology; telemedicine; fitness trackers; sports; exercise; physiology; clinical decision making; vital signs

\section{Introduction}

\section{Background}

Recent years have seen a marked trend of technological innovation through widescale digitization in the areas of health care, sports, and emergency operation services [1-3]. Propelled by technological progress and motivated by improving quality of care while reducing costs, the immense volume of health data produced today holds promise for aiding in ways such as clinical decision support, disease surveillance, health management, and performance optimization [1,4,5]. With a global shift toward personalized, preventative, and evidence-based models of care, the use of noninvasive monitoring and data analysis to inform clinical practice and training program design is steadily increasing $[1,2,6]$.

Owing to the large volume, velocity, and variety of data produced, there has been a need to adopt advanced and complex technology capable of data collection, storage, and analysis [4]. Among these innovative technologies are wearable systems for physiological metrics tracking conceived by the convergence of microelectronics, wireless communication, and analytics. Designated by the Global Observatory for eHealth as mobile health systems, these forms of technology have been recognized by the World Health Organization as an essential element of electronic health, which prioritizes the cost-effective and secure use of digital technologies in support of medical and public health practice $[7,8]$.

Wearables such as the wrist-worn Fitbit (Fitbit Inc) have garnered incredible commercial acceptance, with revenues reaching US \$347 million in the third quarter of $2019[9,10]$. However, despite demonstrating validity, reliability, and acceptability for their estimates of physiological metrics such as heart rate (HR), the use of these devices is largely targeted toward fitness enthusiasts rather than researchers or clinicians [11-13].

Over the past two decades, the increased demand for noninvasive and comfortable long-term tracking of physiological metrics among clinicians has been met through an increase in the research and development of another type of wearable technology known as the smart textile.

Smart textiles are products made up of fibers, filaments, and yarns that host several electronic components, such as sensors, read-out circuits, and embedded communication systems, powered by an integrated or external power supply. Communication systems such as Bluetooth allow for the connectivity of the textile to other intelligent devices for the visualization and analysis of the data obtained in real time. These textile systems, typically designed as electronic-embedded clothing, offer a relaxed structure capable of noninvasive tracking and simultaneous communication of physiological and biomechanical data. In health care, these intelligent textile systems have the ability to support telemedicine and promote the proactive involvement of patients in their medical management through the collection and tracking of their health and diagnostic data [14]. The potential to improve preventative medicine and early diagnosis through the continuous tracking of physical and mental health status as well as physical activity also exists. [14].

In the spheres of sports and emergency response, the ability of these systems to provide continuous physiological data in real time is considerable. The detection and subsequent use of metrics indicative of the physical performance, physiological status, and mental alertness of an athlete or emergency operator have been shown to mitigate injuries and improve performance $[2,15]$. Although wearable systems such as those produced by Catapult (Catapult Innovations) are currently used by sporting teams to monitor workload and impact, these systems are typically limited in the physiological metrics monitored $[6,15,16]$. Smart textiles, on the other hand, have the potential to provide medical personnel and performance specialists with additional comprehensive, physiological insights across multiple body systems.

However, it is currently unclear what type of evidence surrounding the use of smart textiles for physiological parameter monitoring exists. For this reason, a scoping review was conducted to systematically survey the existing body of scientific literature on smart textiles in their most prevalent form, the smart shirt, for the monitoring of physiological parameters.

\section{Objectives}

The primary outcomes were to (1) provide a clear indication of the volume and types of scientific literature relating to smart shirts, (2) summarize the studies completed to date, and (3) identify any knowledge gaps to inform future research.

To guide the review, the following research question was formulated: what is the extent, range, and nature of the scientific literature pertaining to smart shirts for physiological monitoring?

\section{Methods}

\section{Protocol and Registration}

An a priori protocol was developed using the Preferred Reporting Items for Systematic Reviews and Meta-analysis (PRISMA) Extension for Scoping Reviews: Checklist and Explanation [17]. The final protocol was registered prospectively with the Open Science Framework (DOI 10.17605/OSF.IO/TNK9X) on August 8, 2019 [18].

\section{Eligibility Criteria}

The eligibility criteria were informed by the Population-Concept-Context framework recommended by the Joanna Briggs Institute (JBI) Reviewer's Manual [19]. 


\section{Population}

This scoping review did not impose any restrictions on the population. Men and women of any population or age were suitable for inclusion.

\section{Concept}

The concept of this scoping review was the monitoring of physiological outcome measures using smart textiles in the form of smart shirts. For the purpose of this review, a smart textile was defined as an intelligent textile structure or fabric that possesses integrated sensors for the monitoring and recording of physiological parameters while worn.

\section{Context}

All study designs were considered for this scoping review, which included published articles and reviews, conference proceedings, gray literature, and chapters in the text. Studies conducted across all settings were considered for inclusion. Studies were excluded if they focused on a singular component of the smart shirt (ie, materials, sensors, or algorithms) rather than the smart shirt as an integrated unit. Furthermore, because this review focused on physiological parameters, studies concerning smart shirts for biomechanical or activity monitoring were also excluded.

\section{Information Sources}

To identify potentially relevant literature, a 3-step approach was utilized. First, a limited preliminary search was conducted in 2 electronic bibliographic databases relevant to the topic: Ovid Medical Literature Analysis and Retrieval System Online (MEDLINE) and Excerpta Medica database (EMBASE). The limited search was then followed by analysis of the text words contained in the titles and abstracts of the retrieved papers and of the index terms used to describe them. A second comprehensive search strategy was then developed using all identified keywords and index terms by the lead investigator (HK) in consultation with a librarian highly experienced in electronic searches. Using the final search strategy, the following bibliographic databases were searched from inception of the database to June 24, 2019: Ovid MEDLINE, EMBASE, Scopus, Cumulative Index to Nursing and Allied Health Literature, and SPORTDiscus. The search results were exported into EndNote (Clarivate Analytics), with duplicates removed. Finally, the electronic database search was supplemented by scanning the reference lists of the included studies. The Canadian Agency for Drugs and Technologies in Health (CADTH) gray literature searching tool was also used to identify any nonindexed literature of relevance to this review [20].

\section{Search}

The final search strategy for all databases used can be found in Multimedia Appendix 1. Owing to the large number of irrelevant citations returned by the Scopus database, the search strategy was refined through the inclusion of additional keywords using the "AND" operator to focus the returned results on smart shirts for the monitoring of physiological outcome measures.

\section{Selection of Sources of Evidence}

Using a priori eligibility criteria, a standardized questionnaire for study selection was developed to assist in the screening of titles, abstracts, and full text (Multimedia Appendix 2). A pilot exercise preceded each level of screening. Any queries raised by the pilot exercise were reviewed and resulted in the amendment of the questionnaire by the lead investigator. Following the removal of duplicates, the lead investigator screened papers based on title and abstract. Papers that did not meet the eligibility criteria were removed. Subsequently, the full texts of the remaining papers were retrieved and screened to determine their eligibility. As per the PRISMA guidelines, a flow diagram outlining the study selection process was produced (Figure 1). A critical appraisal of individual sources of evidence was not undertaken because this scoping review aimed to provide a map of the extent, range, and nature of the existing evidence rather than seek the best available evidence related to practice or policy [17]. 
Figure 1. Preferred Reporting Items for Systematic Reviews and Meta-analysis flow diagram. CINAHL: The Cumulative Index to Nursing and Allied Health; EMBASE: Excerpta Medica database; MEDLINE: Medical Literature Analysis and Retrieval System Online.
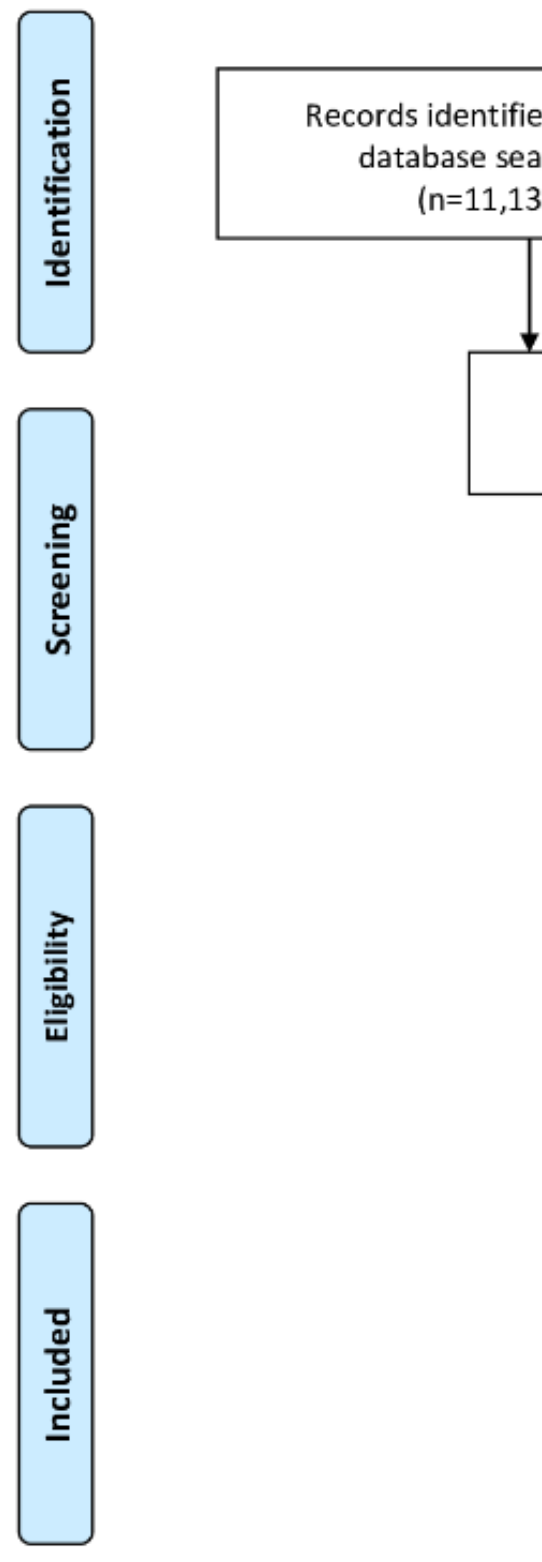

Additional records identified through other sources $(n=36)$

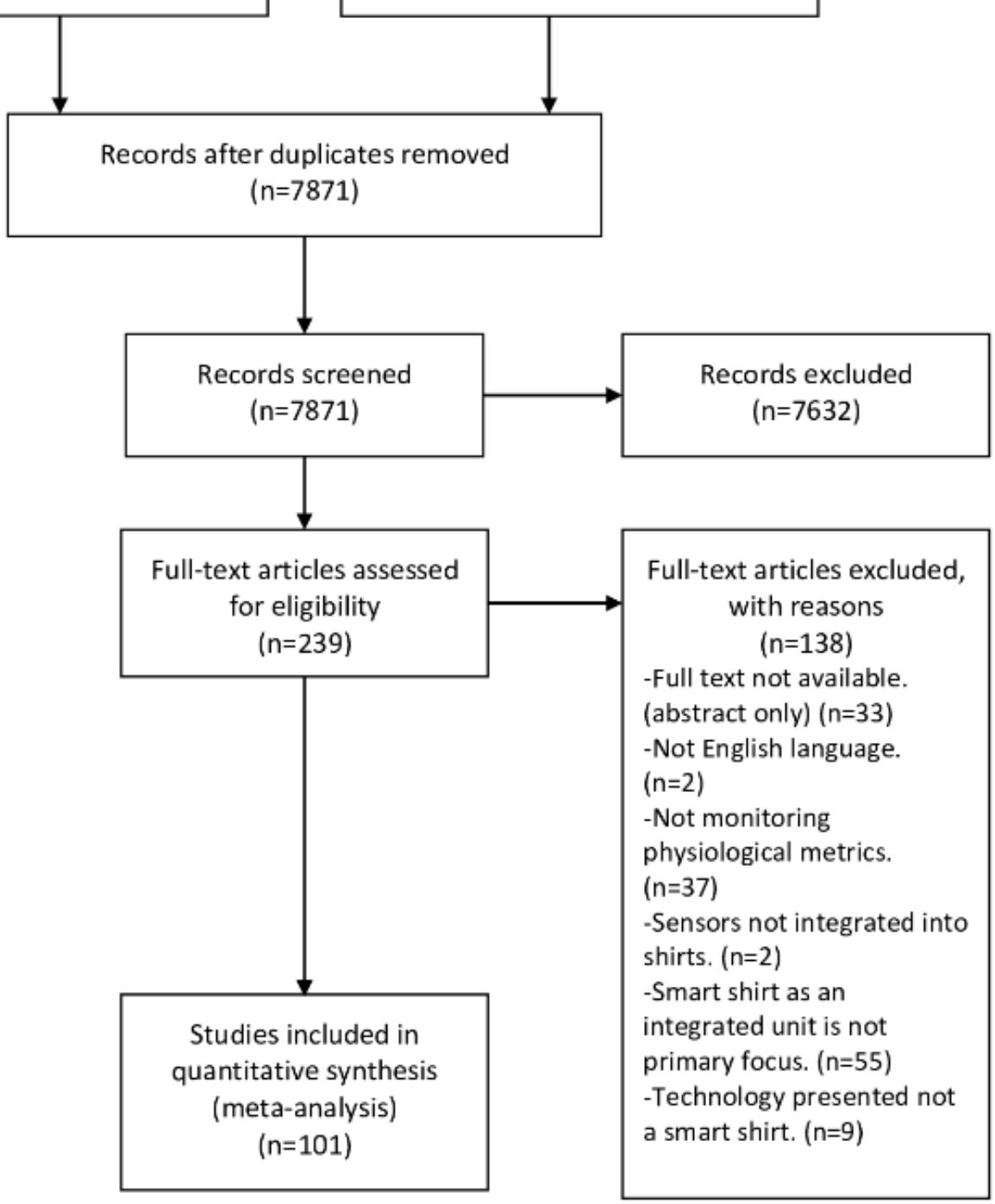

\section{Data Charting and Data Items}

First, a data-charting form was adapted from the JBI Methodology Guidance for Scoping Reviews at the protocol stage [19] (Multimedia Appendix 3). Main areas of interest were identified, such as study citation details (eg, author, year of publication, reference type, country of origin, and study design), key study characteristics (eg, sample characteristics, study aims, type of smart shirt used, comparators, and outcomes measured), and key findings. Once the form was created, it was tested in a pilot data-charting exercise using 10 studies to ensure that all relevant data were being captured. The data extraction fields were updated through an iterative process that resulted in the inclusion of additional fields for thematic analysis (eg, types of signals acquired, and sensors used). Once the testing was complete, and the data-charting form was refined, the lead investigator (HK) independently screened all included studies and extracted key information from them. Data charted in the final extraction form included study citation details (eg, author, year of publication, reference type, country of origin, and study 
design), key study characteristics (eg, sample characteristics, study aims, type of smart shirt used, types of signals acquired, types of sensors used, comparators when applicable, and outcomes measured), and key study findings.

\section{Synthesis of Results}

Studies were categorized according to the four main themes identified: (1) prototype design, (2) validation, (3) observational, and (4) reviews. Key study characteristics and findings are graphically represented and tabulated.

\section{Results}

\section{Selection of Sources of Evidence}

Following the removal of duplicates, a total of 7871 citations were identified from searches of the electronic databases, the CADTH gray literature searching tool, and the reference lists of included studies. On the basis of title and abstract screening, 7632 citations were excluded, whereas 239 were retrieved and assessed for eligibility. Of these, 138 were excluded for the following reasons: 33 were abstracts or the author was unable to retrieve the full text, 2 were in Mandarin, 37 were not focused on physiological parameters collected by smart shirts, 2 included technology that failed the study's definition of a smart shirt due to the lack of integration of their sensors, 55 were focused on only one aspect of a smart shirt (eg, a sensor, materials, or algorithm) rather than the functional unit, and 9 were not smart shirts (eg, chest straps; Figure 1).

\section{General Study Characteristics}

In sorting the included studies by publication type, journal articles were the most prevalent $(60 / 101,59.4 \%)$, followed by conference proceedings $(37 / 101,36.6 \%)$, thesis dissertations $(3 / 101,3.0 \%)$, and reviews $(1 / 101,1.0 \%)$. The years of publication identified in the literature search ranged from 1999 to 2019 , with the years 2015 to 2018 producing the majority of publications $(47 / 101,46.5 \%)$. Publications were categorized into four themes of study: (1) prototype design, (2) validation, (3) observational, and (4) reviews. Table 1 presents the general characteristics and associated references of the analyzed publications, including year of publication, type of publication, and theme of study. The countries of origin varied widely, with 24 countries represented by 5 continents: Europe (61/101, $60.4 \%)$, North America (18/101, 17.8\%), Asia (15/101, 14.9\%), Australia and Oceania (4/101, 4.0\%), and South America (3/101, $3.0 \%$, Table 2 ). Among the 24 countries, Italy produced the bulk of the relevant literature $(25 / 101,24.8 \%)$.

Table 2 presents the countries represented within each continent, their respective references, and the number of studies by theme originating from each country.

Table 1. Characteristics of included studies $(\mathrm{N}=101)$.

\begin{tabular}{|c|c|c|}
\hline Characteristics & $\begin{array}{l}\text { Number of } \\
\text { studies, } n\end{array}$ & Reference(s) \\
\hline \multicolumn{3}{|l|}{ Year of publication } \\
\hline Before 2000 & 1 & {$[21]$} \\
\hline $2000-2004$ & 2 & {$[22]$} \\
\hline $2005-2009$ & 25 & {$[3,23-45]$} \\
\hline 2010-2014 & 18 & [46-63] \\
\hline $2015-2018$ & 47 & [64-111] \\
\hline 2019 & 8 & [112-117] \\
\hline \multicolumn{3}{|l|}{ Type of publication } \\
\hline Journal article & 60 & {$[21-23,25,28,32,34-36,39-43,45,46,49,53,56,59-65,67,69-71,73,74,76,78,80-83,85,86,88-90,93,95-97,99-101,104,106,108,109,114-119]$} \\
\hline $\begin{array}{l}\text { Conference proceed- } \\
\text { ing }\end{array}$ & 37 & {$[3,24,26,27,29-31,33,37,38,44,47,48,50,54,55,57,58,68,72,75,77,79,84,87,92,94,98,102,103,105,107,110,111,113,120]$} \\
\hline Thesis dissertation & 3 & {$[51,66,91]$} \\
\hline Reviews & 1 & [112] \\
\hline \multicolumn{3}{|l|}{ Theme of study } \\
\hline Prototype design & 50 & {$[3,21,22,24-26,31-34,36-40,42-44,47,50,57-60,67-71,77-80,86-90,99-105,114,118,120]$} \\
\hline Validation & 29 & {$[27-29,41,45,46,48,52,53,61-63,72-74,81,92,93,106-111,115-117,119]$} \\
\hline Observational & 21 & {$[23,30,35,49,54-56,64,65,75,76,82-85,94,96-98]$} \\
\hline Review & 1 & [112] \\
\hline
\end{tabular}


Table 2. Countries of origin of the included studies by total and thematic numbers $(\mathrm{N}=101)$.

\begin{tabular}{|c|c|c|c|c|c|}
\hline \multirow[t]{2}{*}{ Continent and country of origin } & \multirow{2}{*}{$\begin{array}{l}\text { Total number of stud- } \\
\text { ies by country, } \mathrm{n}\end{array}$} & \multicolumn{4}{|c|}{ Number of studies by theme } \\
\hline & & $\begin{array}{l}\text { Prototype } \\
\text { design } \\
(n=50)\end{array}$ & $\begin{array}{l}\text { Valida- } \\
\text { tion } \\
(\mathrm{n}=29)\end{array}$ & $\begin{array}{l}\text { Observa- } \\
\text { tional } \\
(n=21)\end{array}$ & $\begin{array}{l}\text { Reviews } \\
(\mathrm{n}=1)\end{array}$ \\
\hline \multicolumn{6}{|l|}{ Europe } \\
\hline Belgium $[32,38]$ & 2 & 2 & N/A ${ }^{a}$ & N/A & N/A \\
\hline Finland [23] & 1 & N/A & N/A & 1 & N/A \\
\hline France $[27,107]$ & 2 & N/A & 2 & N/A & N/A \\
\hline Germany $[42,59,60,63,81,98,105]$ & 7 & 4 & 2 & 1 & N/A \\
\hline Ireland $[31,47]$ & 2 & 2 & N/A & N/A & N/A \\
\hline $\begin{array}{l}\text { Italy } \\
{[3,25,26,29,30,33,36,37,46,48,49,53,54,56,58,64,76,79,84,92,99,108,110,116,120]}\end{array}$ & 25 & 10 & 8 & 7 & N/A \\
\hline Poland $[95,100]$ & 2 & N/A & N/A & 2 & N/A \\
\hline Portugal $[68,71,75,80,102,113]$ & 6 & 6 & N/A & N/A & N/A \\
\hline Slovakia [57] & 1 & 1 & N/A & N/A & N/A \\
\hline Spain $[39,50,62,101]$ & 4 & 3 & 1 & N/A & N/A \\
\hline Switzerland $[28,34,55,72,83,100]$ & 6 & 2 & 2 & 2 & N/A \\
\hline United Kingdom $[45,52,82]$ & 3 & N/A & 2 & 1 & N/A \\
\hline \multicolumn{6}{|l|}{ North America } \\
\hline Canada $[35,74,87,104,114]$ & 5 & 3 & 1 & 1 & N/A \\
\hline United States [21,41,61,65,66,73,85,93,96,97,106,109,117] & 13 & 1 & 8 & 4 & N/A \\
\hline \multicolumn{6}{|l|}{ Asia } \\
\hline China $[40,44,78,88,90]$ & 5 & 5 & N/A & N/A & N/A \\
\hline India [43] & 1 & 1 & N/A & N/A & N/A \\
\hline Japan [70] & 1 & 1 & N/A & N/A & N/A \\
\hline Malaysia [111] & 1 & N/A & 1 & N/A & N/A \\
\hline South Korea $[22,24,69,89,118,119]$ & 6 & 5 & 1 & N/A & N/A \\
\hline Taiwan [67] & 1 & 1 & N/A & N/A & N/A \\
\hline \multicolumn{6}{|l|}{ Australia } \\
\hline Australia [112] & 1 & N/A & N/A & N/A & 1 \\
\hline New Zealand $[91,94,115]$ & 3 & N/A & 1 & 2 & N/A \\
\hline \multicolumn{6}{|l|}{ South America } \\
\hline Chile $[77,86,103]$ & 3 & 3 & N/A & N/A & N/A \\
\hline
\end{tabular}

${ }^{\mathrm{a}}$ N/A: Not applicable.

\section{Study Themes}

\section{Prototype Design Studies}

Throughout the 50 analyzed prototype design studies, the capabilities of the presented smart shirts varied from acquiring one physiological signal (cardiac, respiratory, or surface electromyography [sEMG]) to numerous signals simultaneously (Table 3).

The physiological sensors integrated into the presented prototypes also varied considerably. Across the 50 studies, 10 distinct cardiac and respiratory sensors were identified (Table
4). Among the cardiac sensors, the most prevalent was the textile electrode, which was used in 28 different studies. The piezoresistive sensor, or strain gauge, was the most common respiratory sensor, with its use reported in 10 studies (10/50, $20 \%)$. sEMG electrodes were used in all studies $(4 / 50,8 \%)$, presenting a prototype capable of measuring electrical muscle activity. Other physiological sensors integrated into the prototypes included those capable of measuring body temperature (BT) and blood oxygen saturation $\left(\mathrm{SpO}_{2}\right)$. Table 4 presents all the different sensors identified across all prototype design studies. 
Table 3. Types of signals acquired by the prototypes presented in the included studies $(\mathrm{N}=50)$.

\begin{tabular}{ll}
\hline Signals acquired & Value, $\mathrm{n}(\%)$ \\
\hline Cardiac only $[32,57,60,67-69,78,80,88,105,118]$ & $13(26)$ \\
Respiratory only $[31,42,47,51,79,87,104]$ & $8(16)$ \\
Electromyography only $[38,103]$ & $2(4)$ \\
Numerous signals $[3,22,24-26,33,34,36,37,39,40,44,50,58,59,77,80,86,99,102,113,114,120]$ & $27(54)$ \\
\hline
\end{tabular}

Table 4. Types and prevalence of the physiological sensors used in prototype studies (categories not exclusive; N=81)

\begin{tabular}{|c|c|c|}
\hline Classification and type of sensor & Number of studies, $\mathrm{n}$ & Reference(s) \\
\hline \multicolumn{3}{|l|}{ Cardiac } \\
\hline Adhesive button electrodes & 1 & [22] \\
\hline Bluetooth heart rate monitor & 1 & [67] \\
\hline Noncontact, metal capacitive electrodes & 1 & [69] \\
\hline Conductive ink electrodes & 1 & [70] \\
\hline Disposable electrodes & 1 & [24] \\
\hline Phonocardiogarphy & 1 & [44] \\
\hline Photoplethysmography & 2 & {$[43,44]$} \\
\hline Pulse sensor & 2 & [100] \\
\hline Silicon electrodes & 2 & {$[43,114]$} \\
\hline Textile electrodes & 28 & {$[3,25,26,32-34,36,37,40,50,57,59,60,68,71,77,78,80,86,88-90,99,102,105,113,118,120]$} \\
\hline Not specified & 3 & {$[21,39,58]$} \\
\hline \multicolumn{3}{|l|}{ Respiratory } \\
\hline $\begin{array}{l}\text { Antenna (fiber, spiral, and hybrid spi- } \\
\text { ral) }\end{array}$ & 2 & {$[51,57,104]$} \\
\hline Fiber Bragg grating sensor & 1 & [79] \\
\hline Impedance pneumography & 2 & {$[22,33]$} \\
\hline Noncontact, metal capacitive electrodes & 1 & [101] \\
\hline Optical fiber & 1 & [42] \\
\hline Piezoresistive & 10 & {$[3,25,26,33,36,47,77,86,120]$} \\
\hline Polypyrrole & 1 & [31] \\
\hline Respiratory inductive plethysmography & 5 & {$[34,37,40,44,114]$} \\
\hline Sensor coil & 1 & [59] \\
\hline Textile & 2 & {$[99,102]$} \\
\hline Not specified & 1 & [58] \\
\hline \multicolumn{3}{|l|}{ Electromyography } \\
\hline Surface electromyography electrodes & 4 & {$[38,102,103,113]$} \\
\hline \multicolumn{3}{|l|}{ Oxygen saturation } \\
\hline Pulse oximeter & 2 & {$[46,48]$} \\
\hline Not specified & 1 & [120] \\
\hline \multicolumn{3}{|l|}{ Body temperature } \\
\hline Monolithic & 1 & [3] \\
\hline Bandgap & 1 & {$[50]$} \\
\hline Digital sensor and thermistor & 1 & [43] \\
\hline Not specified & 2 & {$[120]$} \\
\hline
\end{tabular}




\section{Validation Studies}

Following prototype design, validation was the most recurrent study theme. All identified studies investigated the validity of a smart shirt against an established reference technology to measure one or more physiological outcome measures. A total of 16 types of smart shirts were validated (Table 5). Among these were 3 commercially available shirts, Hexoskin (Carrè Technologies Inc), LifeShirt (LifeShirt VivoMetric), and Zephyr BioHarness (Zephyr Technology), and 13 working prototypes. Included in these prototypes was the Protection e-Textiles system developed as part of a European initiative focused on developing a wearable textile system for emergency operators $[46,48]$. The physiological sensors integrated into each shirt varied and ranged from combinations of cardiac, respiratory, BT, and $\mathrm{SpO}_{2}$ sensors. Table 5 presents the outcome measures validated in each smart shirt.

Table 6 summarizes the physiological sensors integrated in each smart shirt. Multimedia Appendix 4 summarizes the validation studies across citation characteristics, study participants, type of smart shirt used, physiological outcome measures validated, reference technology used as a comparator, and main findings.

Table 5. Physiological outcome measures validated by a smart shirt across all validation studies.

\begin{tabular}{|c|c|c|c|c|c|c|c|c|c|}
\hline $\begin{array}{l}\text { Type of smart } \\
\text { shirt }\end{array}$ & $\begin{array}{l}\text { Respiratory } \\
\text { rate }\end{array}$ & $\begin{array}{l}\text { Minute } \\
\text { ventilation }\end{array}$ & $\begin{array}{l}\text { Tidal vol- } \\
\text { ume }\end{array}$ & $\begin{array}{l}\text { Breath } \\
\text { duration }\end{array}$ & $\begin{array}{l}\text { Heart } \\
\text { rate }\end{array}$ & $\begin{array}{l}\text { Electrocardiograph } \\
\text { signals }^{\mathrm{a}}\end{array}$ & $\begin{array}{l}\text { Body tempera- } \\
\text { ture }\end{array}$ & $\begin{array}{l}\text { Blood oxy- } \\
\text { gen satura- } \\
\text { tion }\end{array}$ & $\begin{array}{l}\text { Energy ex- } \\
\text { penditure }\end{array}$ \\
\hline BioShirt & $\mathrm{N} / \mathrm{A}^{\mathrm{b}}$ & N/A & N/A & N/A & N/A & $X^{c}$ & N/A & N/A & N/A \\
\hline GOW system & N/A & N/A & N/A & N/A & N/A & $\mathrm{X}$ & N/A & N/A & N/A \\
\hline $\begin{array}{l}\text { HeartCycle's } \\
\text { guided exercise } \\
\text { system }\end{array}$ & $\mathrm{X}$ & N/A & N/A & N/A & $\mathrm{X}$ & $\mathrm{X}$ & N/A & N/A & N/A \\
\hline Hexoskin & $\mathrm{X}$ & $\mathrm{X}$ & $\mathrm{X}$ & N/A & $\mathrm{X}$ & $\mathrm{X}$ & N/A & N/A & $\mathrm{X}$ \\
\hline $\begin{array}{l}\text { Long Term Medi- } \\
\text { cal Survey Sys- } \\
\text { tem }\end{array}$ & $X$ & N/A & N/A & N/A & $X$ & N/A & $X$ & N/A & N/A \\
\hline $\begin{array}{l}\text { Maglietta Interat- } \\
\text { tiva Computeriz- } \\
\text { zata }\end{array}$ & $X$ & N/A & N/A & N/A & $X$ & $\mathrm{X}$ & N/A & N/A & N/A \\
\hline Prototype 1 [81] & N/A & N/A & N/A & N/A & $\mathrm{X}$ & N/A & N/A & N/A & N/A \\
\hline Prototype 2 [52] & $\mathrm{X}$ & N/A & $\mathrm{X}$ & $\mathrm{X}$ & N/A & N/A & N/A & N/A & N/A \\
\hline Prototype 3 [92] & $X$ & N/A & $X$ & N/A & N/A & N/A & N/A & N/A & N/A \\
\hline Prototype 4 [108] & $X$ & N/A & $X$ & $\mathrm{X}$ & N/A & N/A & N/A & N/A & N/A \\
\hline Prototype 5 [110] & N/A & N/A & N/A & N/A & N/A & N/A & N/A & N/A & N/A \\
\hline $\begin{array}{l}\text { Protection e-Tex- } \\
\text { tiles (inner gar- } \\
\text { ment) }\end{array}$ & N/A & N/A & N/A & N/A & N/A & N/A & $X$ & $\mathrm{X}$ & N/A \\
\hline LifeShirt & $\mathrm{X}$ & N/A & N/A & N/A & N/A & $\mathrm{X}$ & N/A & N/A & N/A \\
\hline Wealthy system & $\mathrm{X}$ & $X$ & N/A & N/A & N/A & N/A & N/A & N/A & N/A \\
\hline $\begin{array}{l}\text { Wearable Well- } \\
\text { ness System }\end{array}$ & N/A & N/A & N/A & N/A & N/A & $X$ & N/A & N/A & N/A \\
\hline $\begin{array}{l}\text { Zephyr Bio- } \\
\text { Harnes }\end{array}$ & N/A & N/A & N/A & N/A & $X$ & N/A & N/A & N/A & N/A \\
\hline
\end{tabular}

${ }^{\mathrm{a}} \mathrm{P}$ and $\mathrm{T}$ waves, QRS complex, respiratory rate intervals, and heart rate variability.

${ }^{\mathrm{b}} \mathrm{N} / \mathrm{A}$ : not applicable.

${ }^{\mathrm{c}} \mathrm{X}$ indicates physiological outcome measures validated by studies for the corresponding smart shirt. 
Table 6. Types of physiological sensors used by smart shirts in the identified validation studies.

\begin{tabular}{|c|c|c|c|}
\hline Smart shirt and category of sensor & Physiological sensors & Number of studies, $\mathrm{n}$ & Reference(s) \\
\hline \multicolumn{4}{|l|}{ BioShirt } \\
\hline $\mathrm{C}^{\mathrm{a}}$ & 1-lead $\mathrm{ECG}^{\mathrm{b}}$ & 1 & {$[119]$} \\
\hline \multicolumn{4}{|l|}{ GOW } \\
\hline $\mathrm{C}$ & 1-lead ECG & 1 & {$[62]$} \\
\hline \multicolumn{4}{|l|}{ HeartCycle's guided exercise } \\
\hline $\mathrm{C}$ & 1-lead ECG & 1 & {$[63]$} \\
\hline $\mathrm{R}^{\mathrm{c}}$ & Not specified & 1 & {$[63]$} \\
\hline \multicolumn{4}{|l|}{ Hexoskin } \\
\hline $\mathrm{C}$ & 1-lead ECG & 10 & {$[65,73,74,93,106,107,109,111,115,117]$} \\
\hline $\mathrm{R}$ & RIP $^{\mathrm{d}}$ & 10 & {$[65,73,74,93,106,107,109,111,115,117]$} \\
\hline \multicolumn{4}{|l|}{ LifeShirt } \\
\hline $\mathrm{C}$ & 2-lead ECG & 3 & {$[28,41,45]$} \\
\hline $\mathrm{R}$ & RIP & 3 & {$[28,41,45]$} \\
\hline \multicolumn{4}{|l|}{ Long Term Medical Survey System } \\
\hline $\mathrm{C}$ & 2-lead ECG & 1 & [72] \\
\hline $\mathrm{R}$ & Transthoracic bioimpedance & 1 & [72] \\
\hline $\mathrm{SpO}_{2}{ }^{\mathrm{e}}$ & 4-channel optical sensor & 1 & [72] \\
\hline $\mathrm{BT}^{\mathrm{f}}$ & $\mathrm{BT}$ & 1 & {$[72]$} \\
\hline \multicolumn{4}{|c|}{ Maglietta Interattiva Computerizzata } \\
\hline $\mathrm{C}$ & 1-lead ECG & 2 & {$[29,53]$} \\
\hline $\mathrm{R}$ & $\begin{array}{l}\text { Piezoresistive plethysmogra- } \\
\text { phy }\end{array}$ & 2 & {$[29,53]$} \\
\hline \multicolumn{4}{|l|}{ Protection e-Textiles } \\
\hline $\mathrm{C}$ & 1-lead ECG & 2 & {$[46,48]$} \\
\hline $\mathrm{R}$ & $\begin{array}{l}\text { Piezoresistive plethysmogra- } \\
\text { phy }\end{array}$ & 2 & {$[46,48]$} \\
\hline $\mathrm{SpO}_{2}$ & Pulse oximeter (finger) & 2 & {$[46,48]$} \\
\hline BT & $\mathrm{N} / \mathrm{A}^{\mathrm{g}}$ & 2 & {$[46,48]$} \\
\hline \multicolumn{4}{|l|}{ Prototype 1} \\
\hline $\mathrm{C}$ & 12-lead ECG & 1 & {$[81]$} \\
\hline \multicolumn{4}{|l|}{ Prototype 2} \\
\hline $\mathrm{C}$ & 1-lead ECG & 1 & {$[52]$} \\
\hline \multicolumn{4}{|l|}{ Prototype 3} \\
\hline $\mathrm{R}$ & $\mathrm{FBG}^{\mathrm{h}}$ & 1 & [92] \\
\hline \multicolumn{4}{|l|}{ Prototype 4} \\
\hline $\mathrm{R}$ & FBG & 1 & [108] \\
\hline \multicolumn{4}{|l|}{ Prototype 5} \\
\hline $\mathrm{R}$ & FBG & 1 & [110] \\
\hline \multicolumn{4}{|l|}{ Wealthy System } \\
\hline $\mathrm{C}$ & 5-lead ECG & 1 & {$[27]$} \\
\hline $\mathrm{R}$ & Impedance pneumography & 1 & {$[27]$} \\
\hline
\end{tabular}




\begin{tabular}{llll}
\hline Smart shirt and category of sensor & Physiological sensors & Number of studies, $\mathrm{n}$ & Reference(s) \\
\hline Wearable Wellness System & & 1 & {$[116]$} \\
C & 1-lead ECG & & \\
Zephyr BioHarness & & 1 & 1-lead ECG \\
R & & $161]$ \\
\hline
\end{tabular}

${ }^{\mathrm{a}} \mathrm{C}$ : cardiac.

${ }^{\mathrm{b}}$ ECG: electrocardiograph.

${ }^{\mathrm{c}} \mathrm{R}$ : respiratory.

${ }^{\mathrm{d}} \mathrm{RIP}$ : respiratory inductance plethysmography.

${ }^{\mathrm{e}} \mathrm{SpO}_{2}$ : blood oxygen saturation.

${ }_{\mathrm{B}} \mathrm{BT}$ : body temperature.

${ }^{\mathrm{g}} \mathrm{N} / \mathrm{A}$ : not applicable.

${ }^{\mathrm{h}} \mathrm{FBG}$ : fiber Bragg grating.

\section{Observational Studies}

Observational studies made up approximately $21.0 \%$ (21/101) of the included publications. These studies used smart shirts to capture various physiological outcome measures in a range of populations. In total, 10 types of smart shirts were used, with Hexoskin being the most prevalent $(8 / 21,38 \%)$, followed by the Personalized Monitoring System for Care in Mental Health system $(3 / 21,14 \%)$. The experimental settings varied among the analyzed studies, with the majority $(13 / 21,62 \%)$ being conducted in the field. A total of 5 studies were conducted in a controlled setting such as a laboratory, whereas 2 used both controlled and free-living settings. The populations studied also varied, with the predominant population being clinical $(9 / 21$, $43 \%)$. The remaining studies used occupational populations such as medical personnel, office employees, firefighters $(5 / 21$, $24 \%)$, healthy participants $(4 / 21,19 \%)$, and a combination of healthy and clinical participants $(3 / 21,14 \%)$. All studies recruited adults with the exception of one that recruited both adults and pediatric participants [95]. Multimedia Appendix 5 summarizes the observational studies across citation characteristics, type of shirt used, study aim, population characteristics, study setting, and physiological outcome measures tracked.

\section{Reviews}

Only one review focusing on the use of smart shirts for the monitoring of physiological parameters was identified through a literature search. This review was in the form of a scoping review with the objectives of exploring, organizing, and presenting the existing literature on the use of electronic textiles for electrocardiograph (ECG) monitoring in cardiac populations. The review identified resting ECG as the most common form of ECG acquired by electronic textiles, followed by exercise ECG and ambulatory ECG. The primary technical issue reported across all studies was noise from motion artifacts [112].

\section{Discussion}

\section{Principal Findings}

The primary purpose of this scoping review was to systematically analyze the body of scientific literature pertaining to smart shirts for the monitoring of physiological parameters.
The primary outcomes were to (1) provide a clear indication of the volume and types of scientific literature relating to smart shirts, (2) summarize the studies completed to date, and (3) identify any knowledge gaps to inform future research.

From the 7871 citations identified after the removal of duplicates, $239(3.00 \%)$ were eligible for full-text review. Of these 239 citations, 101 (1.3\%) were included in the final study. Although the percentage of included studies appears small, this was an expected outcome due to the broad search strategy employed. The reason behind the broad search strategy was the lack of standardized terminology in the field of wearables due to its relatively recent inception. For example, smart textiles may be referred to as electronic textiles, e-textiles, electronic devices, wearable devices, wearable monitoring devices, wearable systems, etc. This required the inclusion of a wide range of keywords in the search strategy to maximize the capturing of relevant literature. However, the limitation of this strategy is that the search resulted in many studies that failed the inclusion criteria.

Throughout the screening and review process, four main themes of study were identified: (1) prototype design, (2) validation, (3) observational, and (4) reviews. The most prominent theme was prototype design, accounting for approximately $49.5 \%$ (50/101) of the total included studies. These studies presented the design of wearable systems in the form of sensor-integrated shirts for continuous and noninvasive monitoring of cardiorespiratory parameters. Although some prototypes were capable of only monitoring a single parameter $(23 / 50,46 \%)$, the majority $(27 / 50,54 \%)$ could monitor several simultaneously. These physiological parameters were classified as cardiac, respiratory, sEMG, $\mathrm{BT}$, and $\mathrm{SpO}_{2}$. Aside from the monitoring capabilities, it was evident that the key focus of design was on the wearability of the smart shirts over longer periods. Many of the established technologies used today for the monitoring of physiological parameters such as the ECG or Holter monitor are only capable of short-term diagnostic recording because of their restricted portability and uncomfortable sensors. To circumvent these issues, many of the included studies integrated their smart shirts with textile sensors. Textile sensors are intended to be comfortable, lightweight, flexible, stretchable, conformable, washable, and long lasting. This contrasts with 
sensors such as the standard single-use, disposable silver-silver chloride $(\mathrm{Ag} / \mathrm{AgCl})$ electrodes, which, in combination with conductive gels, can provoke cutaneous reactions after prolonged skin contact [121]. The $\mathrm{Ag} / \mathrm{AgCl}$ electrodes are also prone to damage after repeated use owing to mechanical stress [121].

Following prototype design, validation was the most identified theme. Validation studies accounted for approximately one-third $(29 / 101,28.7 \%)$ of the total included studies. These studies demonstrated that smart shirts were largely valid in determining cardiorespiratory parameters such as HR and respiratory rate (RR), but showed variable validity when measuring parameters such as energy expenditure $(E E)$, minute ventilation $\left(V_{E}\right)$, and tidal volume $\left(\mathrm{V}_{\mathrm{T}}\right)$ [28,41,107,115,117]. Notably, although maximal oxygen consumption was assessed for reliability in one study, its validity was not evaluated [115]. At the current stage, smart shirts can be considered mostly valid for the measurement of certain physiological parameters under conditions of rest and submaximal activities with variable results at maximal work rate $[62,63,74,93,107,115,117]$. When comparing the number of prototype design and validation studies, it is evident that a large discrepancy exists. The volume of systematic validation research needs to be increased to meet the rate of prototype design studies being published. This is of importance as these wearables are marketed for use by clinicians and researchers who require valid and reliable measures. Moreover, owing to the fluid state of the software used in these devices, which can receive periodic updates, it is important to validate the new algorithm.

The third theme of study identified by this review was observational research, which comprised $20.8 \%$ (21/101) of the total studies. These studies employed a variety of smart shirts in a range of populations, including healthy and clinical as well as specific population subsets such as medical personnel, employees, and emergency operators. A total of 10 distinct smart shirts were utilized, with Hexoskin being the most prevalent. These studies used the data collected by smart shirts for various purposes, such as quantifying stress through heart rate variability (HRV) data in medical personnel and identifying early physiological markers that preceded self-injurious behavior in individuals with intellectual disabilities [35,82,96]. More observational research such as these is required to explore the implementation of smart shirts in live settings and make practical use of the data collected through its processing and analysis. This is the next obvious step in the progression of wearables research.

Finally, only one scoping review was identified in this study, focusing solely on the use of smart textiles for physiological monitoring. As presented in the Results section, this review was restricted to the use of smart textiles for ECG monitoring in cardiac patients.

\section{Gaps in the Literature}

As alluded to in the Principal Findings section, there is a considerable lag between the publication of prototype design and validation studies. Within the area of prototype design, there remains a crucial need to develop sensing technology to further optimize sensor positioning, increase detection sensitivity, and improve the signal-to-noise ratio to assist in moving wearables past the initial prototype stage. In addition, the refinement of algorithms is needed to reduce the risk of overestimating or underestimating values. Furthermore, the diversification of the populations used in validating the prototypes is also needed. Currently, the majority of validation studies include healthy or clinical adults, whereas studies focusing on pediatric populations and specific population subsets such elite athletes and emergency operators are lacking.

Observational research is also largely underrepresented. To understand the capabilities of smart shirts outside of the laboratory, more studies of this nature need to be conducted using a variety of population samples in various settings. These studies should investigate the use of the collected data for meaningful analysis as one issue challenging wearable technology is the translation of its data to create clinically actionable insights. Such insights could take the form of physiological data being collated and reported to a health practitioner on a periodic basis to ensure the optimal management of an outpatient or the implementation of warning signals sent to the patient or health practitioner when the collected data reaches a particular threshold. Although in the sporting realm, teams have begun employing data scientists to disseminate the data into usable metrics, this is largely absent in the clinical sphere. Moving forward, observational studies would be best conducted using a multidisciplinary approach whereby researchers collaborate with the clinicians or professionals expected to implement this technology outside of the laboratory.

\section{Limitations}

This review was limited to publications written in English, which may have excluded key studies published in other languages. This review also focused solely on physiological parameters measured by smart shirts and did not report on any other parameters concerning activity or biomechanics. In addition, the screening, inclusion/exclusion, and data charting stages of this review were conducted by 1 investigator (HK), which could have reduced the likelihood that all relevant studies were identified in the review. The use of 1 investigator may have also resulted in some reviewer bias.

\section{Comparisons With Previous Work}

To the authors' knowledge, this scoping review is the first to systematically map the scientific body of literature surrounding the use of smart textiles in the form of smart shirts for monitoring physiological parameters across all populations. Only one other review that was included in the results investigated the use of smart shirts for monitoring a single physiological parameter [112]. The inclusion criteria of the aforementioned review were limited to smart shirts capable of monitoring ECG signals in cardiac patients, whereas this scoping review included all physiological parameters and population types.

\section{Conclusions}

With the persistent challenges confronting health systems globally and the rising health and safety demands of athletes 
and emergency operators, smart textiles present themselves as a contributor to a possible solution. This scoping review systematically surveyed the existing body of scientific literature pertaining to smart textiles in the form of smart shirts for the monitoring of physiological parameters. Through this review, it was identified that the majority of studies surrounding smart textiles were dedicated to prototype design, whereas validation and observational studies lagged behind considerably. Although smart shirts have been proven to be valid and reliable in the monitoring of some physiological parameters such as HR, HRV, and RR, results were variable for other parameters such as $V_{E}$, $\mathrm{V}_{\mathrm{T}}$, and EE, suggesting a continued need for their systematic validation. Although innovations such as these offer vast potential, it is important to ensure their validity and reliability through careful evaluation before their widespread adoption. To unlock the potential of smart textiles, there is also a need for more observational investigation in collaboration with the professionals expected to implement the technology outside of the laboratory.

\section{Authors' Contributions}

HK, WH, JF, and MC conceived the scoping review. HK performed the scoping review and analyzed the data. HK wrote the paper, and $\mathrm{WH}, \mathrm{JF}$, and MC revised and provided edits contributing to the final manuscript. WH, JF, and MC reviewed and provided feedback for approval of the final manuscript.

\section{Conflicts of Interest}

None declared.

\section{Multimedia Appendix 1}

Search strategies used for each electronic database searched.

[DOCX File, $21 \mathrm{~KB}-$ Multimedia Appendix 1]

\section{Multimedia Appendix 2}

Study selection questionnaire.

[DOCX File, 13 KB-Multimedia Appendix 2]

\section{Multimedia Appendix 3}

Data extraction chart.

[DOCX File, 14 KB-Multimedia Appendix 3]

\section{Multimedia Appendix 4}

Summaries of included validation studies.

[DOCX File , 40 KB-Multimedia Appendix 4]

\section{Multimedia Appendix 5}

Summaries of included observational studies. [DOCX File , 35 KB-Multimedia Appendix 5]

\section{References}

1. Raghupathi W, Raghupathi V. Big data analytics in healthcare: promise and potential. Health Inf Sci Syst 2014;2:3 [FREE Full text] [doi: 10.1186/2047-2501-2-3] [Medline: 25825667]

2. Seshadri DR, Drummond C, Craker J, Rowbottom JR, Voos JE. Wearable devices for sports: new integrated technologies allow coaches, physicians, and trainers to better understand the physical demands of athletes in real time. IEEE Pulse 2017;8(1):38-43. [doi: 10.1109/MPUL.2016.2627240] [Medline: 28129141]

3. Curone D, Dudnik G, Loriga G, Luprano J, Magenes G, Paradiso R, et al. Smart garments for safety improvement of emergency/disaster operators. Conf Proc IEEE Eng Med Biol Soc 2007;2007:3962-3965. [doi: 10.1109/IEMBS.2007.4353201] [Medline: 18002867]

4. Roski J, Bo-Linn GW, Andrews TA. Creating value in health care through big data: opportunities and policy implications. Health Aff (Millwood) 2014 Jul;33(7):1115-1122. [doi: 10.1377/hlthaff.2014.0147] [Medline: 25006136]

5. Chang H. Book review: data-driven healthcare \& analytics in a big data world. Healthc Inform Res 2015;21(1):61-62 PMCID: PMC4330202. [doi: 10.4258/hir.2015.21.1.61]

6. Seshadri DR, Li RT, Voos JE, Rowbottom JR, Alfes CM, Zorman CA, et al. Wearable sensors for monitoring the internal and external workload of the athlete. NPJ Digit Med 2019;2:71 [FREE Full text] [doi: 10.1038/s41746-019-0149-2] [Medline: $\underline{31372506}]$ 
7. World Health Organization. Geneva, Switzerland: WHO; 2018. Seventy-First World Health Assembly (WHA71.7) URL: https://www.who.int/ehealth/about/en/ [accessed 2019-12-02]

8. World Health Organization. mHealth: New Horizons for Health Through Mobile Technologies: Second Global Survey on eHealth. Geneva, Switzerland: WHO Press; 2011.

9. FitBit Inc. 2019 Jun 11. Fitbit Reports Third Quarter Results for the Three Months Ended September 28, 2019 URL: https:/ /investor.fitbit.com/press/press-releases/press-release-details/2019/Fitbit-Reports-Third-Quarter-Results-for-the-ThreeMonths-Ended-September-28-2019/default.aspx [accessed 2020-03-30]

10. Pantelopoulos A, Bourbakis N. A survey on wearable sensor-based systems for health monitoring and prognosis. IEEE Trans Syst Man Cybern C Appl Rev 2010 Jan;40(1):1-12. [doi: 10.1109/TSMCC.2009.2032660]

11. Feehan LM, Geldman J, Sayre EC, Park C, Ezzat AM, Yoo JY, et al. Accuracy of FitBit devices: systematic review and narrative syntheses of quantitative data. JMIR Mhealth Uhealth 2018 Aug 9;6(8):e10527 [FREE Full text] [doi: 10.2196/10527] [Medline: 30093371$]$

12. Thiebaud RS, Funk MD, Patton JC, Massey BL, Shay TE, Schmidt MG, et al. Validity of wrist-worn consumer products to measure heart rate and energy expenditure. Digit Health 2018;4:2055207618770322 [FREE Full text] [doi: 10.1177/2055207618770322] [Medline: 29942628]

13. Burton E, Hill KD, Lautenschlager NT, Thøgersen-Ntoumani C, Lewin G, Boyle E, et al. Reliability and validity of two fitness tracker devices in the laboratory and home environment for older community-dwelling people. BMC Geriatr 2018 May 3;18(1):103 [FREE Full text] [doi: 10.1186/s12877-018-0793-4] [Medline: 29724191]

14. Wang Y, Kung L, Byrd TA. Big data analytics: understanding its capabilities and potential benefits for healthcare organizations. Technol Forecast Soc Change 2018 Jan;126:3-13. [doi: 10.1016/j.techfore.2015.12.019]

15. Li RT, Kling SR, Salata MJ, Cupp SA, Sheehan J, Voos JE. Wearable performance devices in sports medicine. Sports Health 2016;8(1):74-78 [FREE Full text] [doi: 10.1177/1941738115616917] [Medline: 26733594]

16. Wisbey B, Montgomery PG, Pyne DB, Rattray B. Quantifying movement demands of AFL football using GPS tracking. J Sci Med Sport 2010 Sep;13(5):531-536. [doi: 10.1016/j.jsams.2009.09.002] [Medline: 19897414]

17. Tricco AC, Lillie E, Zarin W, O'Brien KK, Colquhoun H, Levac D, et al. PRISMA extension for scoping reviews (PRISMA-ScR): checklist and explanation. Ann Intern Med 2018 Oct 2;169(7):467-473. [doi: 10.7326/M18-0850] [Medline: 30178033]

18. Khundaqji H, Hing W, Furness J, Climstein M. The Open Science Framework. 2019. Smart Shirts for Physiological Monitoring: A Scoping Review URL: https://osf.io/tnk9x/ [accessed 2019-08-19]

19. Peters MD, Godfrey C, McInerney P, Munn Z, Tricco AC, Khalil H. Joanna Briggs Institute Reviewer's Manual. 2020. Chapter 11: Scoping Reviews URL: https://reviewersmanual.joannabriggs.org/ [accessed 2019-08-19]

20. Canadian Agency for Drugs and Technologies in Health. 2019 May 8. Grey Matters: A Practical Tool for Searching Health-Related Grey Literature URL: https://www.cadth.ca/resources/finding-evidence/grey-matters [accessed 2019-06-01]

21. Gopalsamy C, Park S, Rajamanickam R, Jayaraman S. The wearable motherboard: the first generation of adaptive and responsive textile structures (ARTS) for medical applications. Virtual Real 1999 Sep;4(3):152-168. [doi: 10.1007/bf01418152]

22. Shin S, Ryu CY, Kang JH, Nam SH, Song YS, Lim TG, et al. Realization of an e-health system to perceive emergency situations. Conf Proc IEEE Eng Med Biol Soc 2004;2004:3309-3312. [doi: 10.1109/IEMBS.2004.1403930] [Medline: 17270989]

23. Halín N, Junnila M, Loula P, Aarnio P. The LifeShirt system for wireless patient monitoring in the operating room. $\mathbf{J}$ Telemed Telecare 2005;11(Suppl 2):S41-S43. [doi: 10.1258/135763305775124623] [Medline: 16375793]

24. Nam S, Yim T, Ryu C, Shin S, Kang J, Kim S. The preliminary study of unobtrusive respiratory monitoring for e-health. Conf Proc IEEE Eng Med Biol Soc 2005;2005:3796-3798. [doi: 10.1109/IEMBS.2005.1617311] [Medline: 17281056]

25. Paradiso R, Loriga G, Taccini N. A wearable health care system based on knitted integrated sensors. IEEE Trans Inf Technol Biomed 2005 Sep;9(3):337-344. [doi: 10.1109/titb.2005.854512] [Medline: 16167687]

26. Paradiso R, Loriga G, Taccini N. Wearable system for vital signs monitoring. Stud Health Technol Inform 2004;108:253-259. [doi: 10.1109/ITAB.2003.1222533] [Medline: 15718653]

27. Bourdon L, Coli S, Loriga G, Taccini N, Gros B, Gemignani A, et al. First Results With the Wealthy Garment Electrocardiogram Monitoring System. In: Proceedings of the 2005 Computers in Cardiology Conference. 2005 Presented at: CIC'05; September 25-28, 2005; Lyon, France. [doi: 10.1109/cic.2005.1588176]

28. Clarenbach CF, Senn O, Brack T, Kohler M, Bloch KE. Monitoring of ventilation during exercise by a portable respiratory inductive plethysmograph. Chest 2005 Sep;128(3):1282-1290. [doi: 10.1378/chest.128.3.1282] [Medline: 16162719]

29. di Rienzo M, Rizzo F, Parati G, Ferratini M, Brambilla G, Castiglioni P. A Textile-Based Wearable System for Vital Sign Monitoring: Applicability in Cardiac Patients. In: Proceedings of the 2005 Computers in Cardiology Conference. 2005 Presented at: CIC'05; September 25-28, 2005; Lyon, France. [doi: 10.1109/cic.2005.1588199]

30. di Rienzo M, Rizzo F, Meriggi P, Bordoni B, Brambilla G, Ferratini M, et al. Applications of a textile-based wearable system for vital signs monitoring. Conf Proc IEEE Eng Med Biol Soc 2006;2006:2223-2226. [doi: 10.1109/IEMBS.2006.260173] [Medline: 17946505] 
31. Brady S, Carson B, O'Gorman D, Moyna N, Diamond D. Combining Wireless With Wearable Technology for the Development of On-Body Networks. In: Proceedings of the International Workshop on Wearable and Implantable Body Sensor Networks. 2006 Presented at: BSN'06; April 3-5, 2006; Cambridge, MA, USA. [doi: 10.1109/BSN.2006.16]

32. Coosemans J, Hermans B, Puers R. Integrating Wireless ECG Monitoring in Textiles. In: Proceedings of the 13th International Conference on Solid-State Sensors, Actuators and Microsystems. 2005 Presented at: SENSOR'05; June 5-9, 2005; Seoul, South Korea. [doi: 10.1109/SENSOR.2005.1496399]

33. Paradiso R, de Rossi D. Advances in textile technologies for unobtrusive monitoring of vital parameters and movements. Conf Proc IEEE Eng Med Biol Soc 2006;2006:392-395. [doi: 10.1109/IEMBS.2006.259307] [Medline: 17946827]

34. Wilhelm FH, Pfaltz MC, Grossman P. Continuous electronic data capture of physiology, behavior and experience in real life: towards ecological momentary assessment of emotion. Interact Comput 2006 Mar;18(2):171-186. [doi: 10.1016/j.intcom.2005.07.001]

35. Barrera FJ, Violo RA, Graver EE. On the form and function of severe self-injurious behavior. Behav Intervent 2007 Feb;22(1):5-33. [doi: 10.1002/bin.228]

36. Castiglioni P, Faini A, Parati G, di Rienzo M. Wearable seismocardiography. Conf Proc IEEE Eng Med Biol Soc 2007;2007:3954-3957. [doi: 10.1109/IEMBS.2007.4353199] [Medline: 18002865]

37. di Rienzo M, Parati G, Rizzo F, Meriggi P, Merati G, Faini A, et al. Heart rate monitoring and control in altered gravity conditions. Conf Proc IEEE Eng Med Biol Soc 2007;2007:6682-6685. [doi: 10.1109/IEMBS.2007.4353893] [Medline: 18003559]

38. Taelman J, Adriaensen T, van der Horst C, Linz T, Spaepen A. Textile integrated contactless EMG sensing for stress analysis. Conf Proc IEEE Eng Med Biol Soc 2007;2007:3966-3969. [doi: 10.1109/IEMBS.2007.4353202] [Medline: $\underline{18002868]}$

39. Villalba E, Arredondo M, Ottaviano M, Salvi D, Hoyo-Barbolla E, Guillen S. Heart failure monitoring system based on wearable and information technologies. J Commun 2007 Mar 1;2(2):10-21. [doi: 10.4304/jcm.2.2.10-21]

40. Zheng JW, Zhang ZB, Wu TH, Zhang Y. A wearable mobihealth care system supporting real-time diagnosis and alarm. Med Biol Eng Comput 2007 Sep;45(9):877-885. [doi: 10.1007/s11517-007-0221-y] [Medline: 17619091]

41. Heilman KJ, Porges SW. Accuracy of the LifeShirt (Vivometrics) in the detection of cardiac rhythms. Biol Psychol 2007 Jul;75(3):300-305 [FREE Full text] [doi: 10.1016/j.biopsycho.2007.04.001] [Medline: 17540493]

42. D'Angelo L, Weber S, Honda Y, Thiel T, Narbonneau F, Luth TC. A system for respiratory motion detection using optical fibers embedded into textiles. Conf Proc IEEE Eng Med Biol Soc 2008;2008:3694-3697. [doi: 10.1109/IEMBS.2008.4650011] [Medline: 19163514$]$

43. Pandian PS, Mohanavelu K, Safeer KP, Kotresh TM, Shakunthala DT, Gopal P, et al. Smart Vest: wearable multi-parameter remote physiological monitoring system. Med Eng Phys 2008 May;30(4):466-477. [doi: 10.1016/j.medengphy.2007.05.014] [Medline: 17869159 ]

44. Zhang Z, Wang W, Wang B, Wu H, Liu H, Zhang Y. A Prototype of Wearable Respiration Biofeedback Platform and Its Preliminary Evaluation on Cardiovascular Variability. In: Proceedings of the 3rd International Conference on Bioinformatics and Biomedical Engineering. 2009 Presented at: ICBBE'09; June 11-13, 2009; Beijing, China. [doi: 10.1109/icbbe.2009.5162230]

45. Kent L, O'Neill B, Davison G, Nevill A, Elborn JS, Bradley JM. Validity and reliability of cardiorespiratory measurements recorded by the LifeShirt during exercise tests. Respir Physiol Neurobiol 2009 Jun 30;167(2):162-167. [doi: 10.1016/j.resp.2009.03.013] [Medline: 19505672]

46. Curone D, Secco EL, Tognetti A, Loriga G, Dudnik G, Risatti M, et al. Smart garments for emergency operators: the ProeTEX project. IEEE Trans Inf Technol Biomed 2010 May;14(3):694-701. [doi: 10.1109/TITB.2010.2045003] [Medline: 20371413]

47. Carlos R, Coyle S, Corcoran B, Diamond D, Tomas W, Aaron M, et al. Web-Based Sensor Streaming Wearable for Respiratory Monitoring Applications. In: Proceedings of the 2011 SENSORS Conference. 2011 Presented at: ICSENS'11; October 28-31, 2011; Limerick, Ireland. [doi: 10.1109/icsens.2011.6127168]

48. Magenes G, Curone D, Secco EL, Bonfiglio A. Biosensing and environmental sensing for emergency and protection e-textiles. Conf Proc IEEE Eng Med Biol Soc 2011;2011:8365-8368. [doi: 10.1109/IEMBS.2011.6092063] [Medline: 22256287]

49. Migliorini M, Mendez MO, Bianchi AM. Study of heart rate variability in bipolar disorder: linear and non-linear parameters during sleep. Front Neuroeng 2011;4:22 [FREE Full text] [doi: 10.3389/fneng.2011.00022] [Medline: 22291638]

50. Talavera G, Martin R, Rodríguez-Alsina A, Garcia J, Fernández F, Carrabina J. Protecting Firefighters with Wearable Devices. In: Proceedings of the International Conference on Ubiquitous Computing and Ambient Intelligence. 2012 Presented at: UCAmI'12; December 3-5, 2012; Vitoria-Gasteiz, Spain p. 470-477. [doi: 10.1007/978-3-642-35377-2 65]

51. Ratnarathorn S. Semantic Scholar. Gothenburg, Sweden: Chalmers University of Technology; 2012. Design of a Stress Monitor Based on Breathing Signals Using a Smart Textile Shirt URL: https://pdfs.semanticscholar.org/a2bd/ aa838d5333e6d674297d4bf71b0fd709fed1.pdf [accessed 2020-04-03]

52. Cleland I, Nugent C, Finlay D, Burns W, Bougourd J, Armitage R. Assessment of Custom Fitted Heart Rate Sensing Garments whilst undertaking Everyday Activities. In: Proceedings of the International Conference on Smart Homes and 
Health Telematics. 2012 Presented at: ICOST'12; June 12-15, 2012; Artiminio, Italy p. 124-131. [doi: 10.1007/978-3-642-30779-9 16]

53. di Rienzo M, Racca V, Rizzo F, Bordoni B, Parati G, Castiglioni P, et al. Evaluation of a textile-based wearable system for the electrocardiogram monitoring in cardiac patients. Europace 2013 Apr;15(4):607-612. [doi: 10.1093/europace/eus368] [Medline: 23258818]

54. di Rienzo M, Vaini E, Castiglioni P, Lombardi P, Meriggi P, Rizzo F. A textile-based wearable system for the prolonged assessment of cardiac mechanics in daily life. Conf Proc IEEE Eng Med Biol Soc 2014;2014:6896-6898. [doi: 10.1109/EMBC.2014.6945213] [Medline: 25571581]

55. Mirmohamadsadeghi L, Fallet S, Buttu A, Saugy J, Saugy T, Heinzer R, et al. Sleep Apnea Detection Using Features From the Respiration and the ECG Recorded With Smart-Shirts. In: Proceedings of the 2014 Biomedical Circuits and Systems Conference. 2014 Presented at: BioCAS'14; October 22-24, 2014; Lausanne, Switzerland. [doi: 10.1109/biocas.2014.6981645]

56. Valenza G, Nardelli M, Lanatà A, Gentili C, Bertschy G, Paradiso R, et al. Wearable monitoring for mood recognition in bipolar disorder based on history-dependent long-term heart rate variability analysis. IEEE J Biomed Health Inform 2014 Sep;18(5):1625-1635. [doi: 10.1109/JBHI.2013.2290382] [Medline: 24240031]

57. Hanic M, Sládek L, Horínek F, Jagelka M, Donoval M, Dařícek M, et al. BIO-Monitoring System With Conductive Textile Electrodes Integrated Into T-Shirt. In: Proceedings of the 24th International Conference Radioelektronika. 2014 Presented at: Radioelek'14; April 15-16, 2014; Bratislava, Slovakia. [doi: 10.1109/radioelek.2014.6828472]

58. Sardini E, Serpelloni M. T-Shirt for Vital Parameter Monitoring. In: Proceedings of the First National Conference on Sensors. 2014 Presented at: SENSORS'14; February 15-17, 2014; Rome p. 201-205. [doi: 10.1007/978-1-4614-3860-1_35]

59. Teichmann D, Kuhn A, Leonhardt S, Walter M. The MAIN shirt: a textile-integrated magnetic induction sensor array. Sensors (Basel) 2014 Jan 9;14(1):1039-1056 [FREE Full text] [doi: 10.3390/s140101039] [Medline: 24412900]

60. Ulbrich M, Mühlsteff J, Sipilä A, Kamppi M, Koskela A, Myry M, et al. The IMPACT shirt: textile integrated and portable impedance cardiography. Physiol Meas 2014 Jun;35(6):1181-1196. [doi: 10.1088/0967-3334/35/6/1181] [Medline: 24846072]

61. Dolezal BA, Boland DM, Carney J, Abrazado M, Smith DL, Cooper CB. Validation of heart rate derived from a physiological status monitor-embedded compression shirt against criterion ECG. J Occup Environ Hyg 2014;11(12):833-839. [doi: 10.1080/15459624.2014.925114] [Medline: 24896644]

62. Romagnoli M, Alis R, Guillen J, Basterra J, Villacastin JP, Guillen S. A novel device based on smart textile to control heart's activity during exercise. Australas Phys Eng Sci Med 2014 Jun;37(2):377-384. [doi: 10.1007/s13246-014-0271-z] [Medline: 24756693]

63. Skobel E, Martinez-Romero A, Scheibe B, Schauerte P, Marx N, Luprano J, et al. Evaluation of a newly designed shirt-based ECG and breathing sensor for home-based training as part of cardiac rehabilitation for coronary artery disease. Eur J Prev Cardiol 2014 Nov;21(11):1332-1340. [doi: 10.1177/2047487313493227] [Medline: 23733743]

64. Lanata A, Valenza G, Nardelli M, Gentili C, Scilingo EP. Complexity index from a personalized wearable monitoring system for assessing remission in mental health. IEEE J Biomed Health Inform 2015 Jan;19(1):132-139. [doi: 10.1109/JBHI.2014.2360711] [Medline: 25291802]

65. Montes J, Stone TM, Manning JW, McCune D, Tacad DK, Young JC, et al. Using hexoskin wearable technology to obtain body metrics during trail hiking. Int J Exerc Sci 2015;8(4):425-430 [FREE Full text] [doi: 10.1249/01.mss.0000477034.13469.88] [Medline: 27293503]

66. Montes J. Digital Scholarship. 2015. Validation and Reliability of the Hexoskin and FitBit Flex Wearable BIO Collection Devices URL: https://digitalscholarship.unlv.edu/thesesdissertations/2393/ [accessed 2020-04-03]

67. Hsiao C, Lee R, Tien S, Feng Y, Huang S. Early clinical prognosis for high-risk chest pain patients using smart textiles. Biomed Eng Appl Basis Commun 2015;27(6):1550057. [doi: 10.4015/s101623721550057x]

68. Lage JE, Catarino AP, Carvalho H, Rocha A. Smart Shirt With Embedded Vital Sign and Moisture Sensing. In: Proceedings of the First International Conference on Smart Portable, Wearable, Implantable and Disability-oriented Devices and Systems. 2015 Presented at: SPWID'15; June 21 - 26, 2015; Brussels, Belgium URL: https://www.semanticscholar.org/paper/ Smart-shirt-with-embedded-vital-sign-and-moisture-Lage-Catarino/e22968b24987b6bce82f9cd67b5918a93885b896

69. Mathias DN, Kim S, Park J, Joung Y. Real time ECG monitoring through a wearable smart t-shirt. Trans Electr Electron Mater 2015 Feb 25;16(1):16-19. [doi: 10.4313/teem.2015.16.1.16]

70. Tada Y, Amano Y, Sato T, Saito S, Inoue M. A smart shirt made with conductive ink and conductive foam for the measurement of electrocardiogram signals with unipolar precordial leads. Fibers 2015 Nov 3;3(4):463-477. [doi: 10.3390/fib3040463]

71. Trindade I, Martins F, Dias R, Oliveira C, da Silva JM. Novel textile systems for the continuous monitoring of vital signals: design and characterization. Conf Proc IEEE Eng Med Biol Soc 2015 Aug;2015:3743-3746. [doi: 10.1109/EMBC.2015.7319207] [Medline: 26737107]

72. Chételat O, Ferrario D, Proença M, Porchet JA, Falhi A, Grossenbacher O, et al. Clinical validation of LTMS-S: a wearable system for vital signs monitoring. Conf Proc IEEE Eng Med Biol Soc 2015;2015:3125-3128. [doi: 10.1109/EMBC.2015.7319054] [Medline: 26736954] 
73. Tanner EA, Montes J, Manning JW, Taylor JE, DeBeliso M, Young JC, et al. Validation of Hexoskin biometric shirt to COSMED K4 b2 metabolic unit in adults during trail running. Sport Technol 2015;8(3-4):118-123. [doi: $\underline{10.1080 / 19346182.2016 .1248973}$

74. Villar R, Beltrame T, Hughson RL. Validation of the Hexoskin wearable vest during lying, sitting, standing, and walking activities. Appl Physiol Nutr Metab 2015 Oct;40(10):1019-1024. [doi: 10.1139/apnm-2015-0140] [Medline: 26360814]

75. Paiva J, Rodrigues S, Cunha JP. Changes in ST, QT and RR ECG intervals during acute stress in firefighters: a pilot study. Conf Proc IEEE Eng Med Biol Soc 2016 Aug;2016:3378-3381. [doi: 10.1109/EMBC.2016.7591452] [Medline: 28269028]

76. Valenza G, Nardelli M, Lanata' A, Gentili C, Bertschy G, Kosel M, et al. Predicting mood changes in bipolar disorder through heartbeat nonlinear dynamics. IEEE J Biomed Health Inform 2016 Jul;20(4):1034-1043. [doi: 10.1109/JBHI.2016.2554546] [Medline: 28113920]

77. Aqueveque P, Gutierrez C, Saavedra F, Pino EJ. Noninvasive health condition monitoring device for workers at high altitudes conditions. Conf Proc IEEE Eng Med Biol Soc 2016 Aug;2016:2349-2352. [doi: 10.1109/EMBC.2016.7591201] [Medline: 28268797]

78. Dai M, Xiao X, Chen X, Lin H, Wu W, Chen S. A low-power and miniaturized electrocardiograph data collection system with smart textile electrodes for monitoring of cardiac function. Australas Phys Eng Sci Med 2016 Dec;39(4):1029-1040. [doi: 10.1007/s13246-016-0483-5] [Medline: 27743384]

79. Massaroni C, Ciocchetti M, di Tomaso G, Saccomandi P, Caponero MA, Polimadei A, et al. Design and preliminary assessment of a smart textile for respiratory monitoring based on an array of Fiber Bragg Gratings. Conf Proc IEEE Eng Med Biol Soc 2016 Aug;2016:6054-6057. [doi: 10.1109/EMBC.2016.7592109] [Medline: 28269633]

80. Trindade IG, da Silva JM, Miguel R, Pereira M, Lucas J, Oliveira L, et al. Design and evaluation of novel textile wearable systems for the surveillance of vital signals. Sensors (Basel) 2016 Sep 24;16(10):1573 [FREE Full text] [doi:

10.3390/s16101573] [Medline: 27669263]

81. Boehm A, Yu X, Neu W, Leonhardt S, Teichmann D. A novel 12-lead ECG t-shirt with active electrodes. Electron 2016 Nov 8;5(4):75. [doi: 10.3390/electronics5040075]

82. Chatty L, Omurtag A, Roy R, Garbey M. Tracking Mental Workload by Multimodal Measurements During Minimally Invasive Surgery Training. In: Proceedings of the 2017 Scientific Session of the Society of American Gastrointestinal and Endoscopic Surgeons. 2017 Presented at: SAGES'17; March 22-25, 2017; Houston, Texas URL: https://www.sages.org/ meetings/annual-meeting/abstracts-archive/tracking-mental-workload-by-multimodal-measurements-duringminimally-invasive-surgery-training/ [doi: 10.1007/s00464-017-5445-9]

83. Palix J, Akselrod M, Cungi C, Giuliani F, Favrod J. Changes in heart rate variability recorded in natural situation with t-shirt integrated sensors and level of observed behavioral excitation: a pilot study of patients with intellectual disabilities and psychiatric disorders. Front Psychiatry 2017;8:4 [FREE Full text] [doi: 10.3389/fpsyt.2017.00004] [Medline: 28203208]

84. Presti DL, Massaroni C, Formica D, Giurazza F, Schena E, Saccomandi P, et al. Respiratory and Cardiac Rates Monitoring During MR Examination by a Sensorized Smart Textile. In: Proceedings of the International Instrumentation and Measurement Technology Conference. 2017 Presented at: I2MTC'17; May 22-25, 2017; Turin, Italy. [doi: 10.1109/i2mtc.2017.7969818]

85. Webster E, Sukaviriya N, Chang H, Kozloski J. Predicting cognitive states from wearable recordings of autonomic function. IBM J Res Dev 2017 Mar 1;61(2/3):2:1-2:11. [doi: 10.1147/jrd.2017.2648698]

86. Aqueveque P, Gutierrez C, Rodriguez FS, Pino EJ, Morales AS, Wiechmann EP. Monitoring physiological variables of mining workers at high altitude. IEEE Trans Ind Appl 2017 May;53(3):2628-2634. [doi: 10.1109/tia.2017.2675360]

87. Gorgutsa S, Bellemare-Rousseau S, Guay P, Miled A, Messaddeq Y. Smart T-Shirt With Wireless Respiration Sensor. In: Proceedings of the 2017 Conference on IEEE Sensors. 2017 Presented at: ICSENS'17; October 29-November 1, 2017; Glasgow, UK. [doi: 10.1109/icsens.2017.8234293]

88. Zhang H, Tian L, Lu H, Zhou M, Zou H, Fang P, et al. A wearable 12-lead ECG acquisition system with fabric electrodes. Conf Proc IEEE Eng Med Biol Soc 2017 Jul;2017:4439-4442. [doi: 10.1109/EMBC.2017.8037841] [Medline: 29060882]

89. Park J, Han H, Heo J, Lee J. Computer aided diagnosis sensor integrated outdoor shirts for real time heart disease monitoring. Comput Assist Surg (Abingdon) 2017 Dec;22(Supl 1):176-185. [doi: 10.1080/24699322.2017.1389396] [Medline: 29037055]

90. Sun F, Yi C, Li W, Li Y. A wearable H-shirt for exercise ECG monitoring and individual lactate threshold computing. Comput Ind 2017 Nov;92-93:1-11. [doi: 10.1016/j.compind.2017.06.004]

91. Baig MM. AUT Library. Auckland, New Zealand: Auckland University of Technology; 2017. Early Detection and Self-Management of Long-Term Conditions Using Wearable Technologies URL: https://openrepository.aut.ac.nz/handle/ 10292/10999?show=full [accessed 2020-04-03]

92. Lo Presti D, Massaroni C, Saccomandi P, Caponero MA, Formica D, Schena E. A wearable textile for respiratory monitoring: feasibility assessment and analysis of sensors position on system response. Conf Proc IEEE Eng Med Biol Soc 2017 Jul;2017:4423-4426. [doi: 10.1109/EMBC.2017.8037837] [Medline: 29060878]

93. Montoye AH, Mitrzyk JR, Molesky MJ. Comparative accuracy of a wrist-worn activity tracker and a smart shirt for physical activity assessment. Meas Phys Educ Exerc Sci 2017 Jun 8;21(4):201-211. [doi: 10.1080/1091367x.2017.1331166]

94. Baig M, Mirza F, GholamHosseini H, Gutierrez J, Ullah E. Clinical decision support for early detection of prediabetes and type 2 diabetes mellitus using wearable technology. Conf Proc IEEE Eng Med Biol Soc 2018 Jul;2018:4456-4459. [doi: 10.1109/EMBC.2018.8513343] [Medline: 30441340] 
95. Balsam P, Lodziński P, Tymińska A, Ozierański K, Januszkiewicz L, Główczyńska R, et al. Study design and rationale for biomedical shirt-based electrocardiography monitoring in relevant clinical situations: ECG-shirt study. Cardiol J 2018;25(1):52-59 [FREE Full text] [doi: 10.5603/CJ.a2017.0102] [Medline: 28840587]

96. Slamon NB, Penfil SH, Nadkarni VM, Parker RM. A prospective pilot study of the biometrics of critical care practitioners during live patient care using a wearable 'smart shirt'. J Intensive Crit Care 2018;4(2):10. [doi: 10.21767/2471-8505.100112]

97. Thompson JF, Severson RL, Rosecrance JC. Occupational physical activity in brewery and office workers. J Occup Environ Hyg 2018 Sep;15(9):686-699. [doi: 10.1080/15459624.2018.1492136] [Medline: 30188781]

98. Yu X, Boehm A, Neu W, Venema B, Marx N, Leonhardt S, et al. A Wearable 12-Lead ECG T-Shirt With Textile Electrodes for Unobtrusive Long-Term Monitoring-Evaluation of an Ongoing Clinical Trial. In: Proceedings of the 2017 European Medical and Biological Engineering Confernce. 2017 Presented at: EMBEC'17; June 11-15, 2017; Tampere, Finland p. 703-706. [doi: 10.1007/978-981-10-5122-7 176]

99. di Rienzo M, Vaini E, Lombardi P. Development of a smart garment for the assessment of cardiac mechanical performance and other vital signs during sleep in microgravity. Sens Actuators A Phys 2018 May;274:19-27. [doi: 10.1016/j.sna.2018.02.034]

100. Kańtoch E. Recognition of sedentary behavior by machine learning analysis of wearable sensors during activities of daily living for telemedical assessment of cardiovascular risk. Sensors (Basel) 2018 Sep 24;18(10):E3219 [FREE Full text] [doi: 10.3390/s18103219] [Medline: 30249987]

101. Naranjo-Hernández D, Talaminos-Barroso A, Reina-Tosina J, Roa L, Barbarov-Rostan G, Cejudo-Ramos P, et al. Smart vest for respiratory rate monitoring of COPD patients based on non-contact capacitive sensing. Sensors (Basel) 2018 Jul 3;18(7):2144 [FREE Full text] [doi: 10.3390/s18072144] [Medline: 29970861]

102. Paiva A, Ferreira F, Catarino A, Carvalho M, Carvalho H. Design of smart garments for sports and rehabilitation. IOP Conf Ser Mater Sci Eng 2018 Dec 7;459:12083. [doi: 10.1088/1757-899X/459/1/012083]

103. Pino E, Arias Y, Aqueveque P. Wearable EMG shirt for upper limb training. Conf Proc IEEE Eng Med Biol Soc 2018 Jul;2018:4406-4409. [doi: 10.1109/EMBC.2018.8513107] [Medline: 30441329]

104. Roudjane M, Bellemare-Rousseau S, Khalil M, Gorgutsa S, Miled A, Messaddeq Y. A portable wireless communication platform based on a multi-material fiber sensor for real-time breath detection. Sensors (Basel) 2018 Mar 25;18(4):973 [FREE Full text] [doi: 10.3390/s18040973] [Medline: 29587396]

105. Walzer T, Thies C, Meier K, Madrid NM. Textile Sensor Platform (TSP)-Development of a Textile Real-Time Electrocardiogram. In: Proceedings of the 2018 International Conference on Bioinformatics and Biomedical Engineering. 2018 Presented at: IWBBIO'18; April 25-27, 2018; Granada, Spain p. 359-370. [doi: 10.1007/978-3-319-78759-6 33]

106. Banerjee T, Peterson M, Oliver Q, Froehle A, Lawhorne L. Validating a commercial device for continuous activity measurement in the older adult population for dementia management. Smart Health (Amst) 2018 Jan;5-6:51-62 [FREE Full text] [doi: 10.1016/j.smhl.2017.11.001] [Medline: 29915807]

107. Cherif NH, Mezghani N, Gaudreault N, Ouakrim Y, Mouzoune I, Boulay P. Physiological Data Validation of the Hexoskin Smart Textile. In: Proceedings of the 11th International Conference on Biomedical Electronics and Devices. 2018 Presented at: BIODEVICES'18; January 19-21, 2018; Funchal, Portugal p. 150-156. [doi: 10.5220/0006588001500156]

108. Massaroni C, Venanzi C, Silvatti AP, Lo Presti D, Saccomandi P, Formica D, et al. Smart textile for respiratory monitoring and thoraco-abdominal motion pattern evaluation. J Biophotonics 2018 May;11(5):e201700263. [doi: 10.1002/jbio.201700263] [Medline: 29297202]

109. Montes J, Young JC, Tandy R, Navalta JW. Reliability and validation of the hexoskin wearable bio-collection device during walking conditions. Int J Exerc Sci 2018;11(7):806-816 [FREE Full text] [doi: 10.1519/JSC.0000000000002005] [Medline: $\underline{30338022]}$

110. Presti DL, Massaroni C, Schena PS, Formica D, Caponero MA, di Tomaso G. Smart Textile Based on FBG Sensors for Breath-by-Breath Respiratory Monitoring: Tests on Women. In: Proceedings of the 2018 IEEE International Symposium on Medical Measurements and Applications. 2018 Presented at: MeMeA'18; June 11-13, 2018; Rome, Italy. [doi: 10.1109/memea.2018.8438721]

111. Tan DY, Yong TH. Suitability of SmartShirt by Hexoskin to Monitor Heart Rate for Racket Sports. In: Proceedings of the 2017 International Conference on Robotics, Automation and Sciences. 2017 Presented at: ICORAS'17; November 27-29, 2017; Melaka, Malaysia. [doi: 10.1109/icoras.2017.8308057]

112. Teferra MN, Kourbelis C, Newman P, Ramos JS, Hobbs D, Clark RA, et al. Electronic textile electrocardiogram monitoring in cardiac patients: a scoping review protocol. JBI Database System Rev Implement Rep 2019 Feb;17(2):147-156. [doi: 10.11124/JBISRIR-2017-003630] [Medline: 30204712]

113. Paiva A, Catarino A, Carvalho H, Postolache O, Postolache G, Ferreira F. Design of a Long Sleeve T-Shirt with ECG and EMG for Athletes and Rehabilitation Patients. In: Proceedings of the 2018 International Conference on Innovation, Engineering and Entrepreneurship. 2018 Presented at: HELIX'18; June 27-29, 2018; Guimarães, Portugal p. 244-250. [doi: 10.1007/978-3-319-91334-6 34]

114. Steinberg C, Philippon F, Sanchez M, Fortier-Poisson P, O'Hara G, Molin F, et al. A novel wearable device for continuous ambulatory ECG recording: proof of concept and assessment of signal quality. Biosensors (Basel) 2019 Jan 21;9(1):17 [FREE Full text] [doi: 10.3390/bios9010017] [Medline: 30669678] 
115. Elliot CA, Hamlin MJ, Lizamore CA. Validity and reliability of the hexoskin wearable biometric vest during maximal aerobic power testing in elite cyclists. J Strength Cond Res 2019 May;33(5):1437-1444. [doi: 10.1519/JSC.0000000000002005] [Medline: 28759538]

116. Reali P, Tacchino G, Rocco G, Cerutti S, Bianchi AM. Heart rate variability from wearables: a comparative analysis among standard ECG, a smart shirt and a wristband. Stud Health Technol Inform 2019;261:128-133. [doi: 10.3233/978-1-61499-975-1-128] [Medline: 31156103]

117. Smith CM, Chillrud SN, Jack DW, Kinney P, Yang Q, Layton AM. Laboratory validation of hexoskin biometric shirt at rest, submaximal exercise, and maximal exercise while riding a stationary bicycle. J Occup Environ Med 2019 Apr;61(4):e104-e111. [doi: 10.1097/JOM.0000000000001537] [Medline: 30946696]

118. Lee Y, Chung W. Wireless sensor network based wearable smart shirt for ubiquitous health and activity monitoring. Sens Actuators B Chem 2009 Jul;140(2):390-395. [doi: 10.1016/j.snb.2009.04.040]

119. Hong S, Yang Y, Kim S, Shin S, Lee I, Jang Y, et al. Performance study of the wearable one-lead wireless electrocardiographic monitoring system. Telemed J E Health 2009 Mar;15(2):166-175. [doi: 10.1089/tmj.2008.0071] [Medline: 19292626]

120. Magenes G, Curone D, Lanati M, Secco EL. Long-distance monitoring of physiological and environmental parameters for emergency operators. Conf Proc IEEE Eng Med Biol Soc 2009;2009:5159-5162. [doi: 10.1109/IEMBS.2009.5332737] [Medline: $\underline{19963886}$ ]

121. Ankhili A, Tao X, Cochrane C, Coulon D, Koncar V. Washable and reliable textile electrodes embedded into underwear fabric for electrocardiography (ECG) monitoring. Materials (Basel) 2018 Feb 7;11(2):256 [FREE Full text] [doi: 10.3390/ma11020256] [Medline: 29414849]

\author{
Abbreviations \\ Ag: silver \\ AgCl: silver chloride \\ BT: body temperature \\ CADTH: Canadian Agency for Drugs and Technologies in Health \\ ECG: electrocardiograph \\ EE: energy expenditure \\ EMBASE: Excerpta Medica database \\ HR: heart rate \\ HRV: heart rate variability \\ JBI: Joanna Briggs Institute \\ MEDLINE: Medical Literature Analysis and Retrieval System Online \\ PRISMA: Preferred Reporting Items for Systematic Reviews and Meta-analysis \\ RR: respiratory rate \\ sEMG: surface electromyography \\ $\mathrm{SpO}_{2}$ : blood oxygen saturation \\ VE: minute ventilation \\ VT: tidal volume
}

Edited by G Eysenbach; submitted 03.02.20; peer-reviewed by M DeBeliso, K Pirzada; comments to author 07.03.20; revised version
received 10.03.20; accepted 22.03.20; published 27.05.20
Please cite as:
Khundaqji H, Hing W, Furness J, Climstein M
Smart Shirts for Monitoring Physiological Parameters: Scoping Review
JMIR Mhealth Uhealth 2020;8(5):e18092
URL: http://mhealth.jmir.org/2020/5/e18092/
doi: $\underline{10.2196 / 18092}$
PMID: $\underline{32348279}$

(CHamzeh Khundaqji, Wayne Hing, James Furness, Mike Climstein. Originally published in JMIR mHealth and uHealth (http://mhealth.jmir.org), 27.05.2020. This is an open-access article distributed under the terms of the Creative Commons Attribution License (https://creativecommons.org/licenses/by/4.0/), which permits unrestricted use, distribution, and reproduction in any medium, provided the original work, first published in JMIR mHealth and uHealth, is properly cited. The complete bibliographic 
information, a link to the original publication on http://mhealth.jmir.org/, as well as this copyright and license information must be included. 